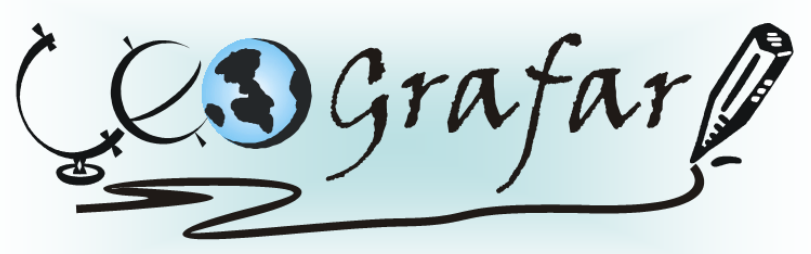

Revista Eletrônica do Programa de Pós-Graduação em Geografia - UFPR

\title{
A ATIVIDADE CANAVIEIRA NO BRASIL: O ESTADO, A AGRO- INDÚSTRIA E OS TRABALHADORES DA CANA-DE-AÇÚCAR
}

\author{
VITOR HUGO RIBEIRO ${ }^{1}$ \\ CELENE TONELLA ${ }^{2}$
}

RESUMO: Por trás de toda atividade econômica, existe uma série de agentes sociais envolvidos no processo de produção, bem como no processo de acumulação de capital. Dentre os principais agentes, o Estado aparece como sendo o mais importante, na medida em que serve de controle de antagonismos de classes e, em muitos casos, diante de pressões, benefícios são canalizados para atendimentos de segmentos hegemônicos do capital. O presente artigo trata da atividade econômica ligada à cana-de-açúcar e foca o comportamento do Estado, da perspectiva dos agroindustriais e dos trabalhadores da cana-de-açúcar.

Palavras-chave: Estado, Agroindústria Canavieira, Trabalhadores Rurais .

\section{THE SUGAR CANE ACTIVITY IN BRAZIL: THE STATE, THE AGRIBUSINESS AND THE WORKERS OF THE SUGAR CANE}

\begin{abstract}
Behind all economic activity there are a lot of social agents involved in the production process, as well as in the process of the capital accumulation. Among the main agents, the State appears as being the most important in the control of antagonisms of social classes, and in many cases in front of pressures, benefits are canalized to attending of the capital hegemonic segments. The present article treats about the economic activity linked to the sugar cane and directs to the relation of the State, in the perspective of the agribusiness men and the workers of the sugar cane. Key-word: State, agribusiness of the sugar cane, agricultural workers.
\end{abstract}

\section{INTRODUÇÃO}

Este artigo foi resultado de pesquisas teóricas baseadas em leituras de autores que refletiram a relação do Estado Brasileiro com o setor agroindustrial canavieiro e com os trabalhadores rurais ligados a esse setor, e teve por objetivo discutir a relação entre os principais agentes sociais (Estado, capitalistas e trabalhadores) que envolve a economia canavieira no País.

\footnotetext{
${ }^{1}$ Mestrando em Geografia pela Universidade Estadual de Maringá, integrante do Núcleo de Estudos de Mobilidade e Mobilização NEMO- UEM.

${ }^{2}$ Doutora em História, e professora do Departamento de Ciências Sociais e da Pós-Graduação em Geografia da Universidade Estadual de Maringá, pesquisadora da Rede Observatório das Metrópoles, Institutos Nacionais- CNPQ.
} 
A problemática posta em questão é uma crítica acerca das políticas públicas do Estado para com os trabalhadores rurais, pois como se verá no decorrer do texto, as principais políticas por parte do governo federal, em diferentes épocas da história desta atividade no País, têm se voltado apenas ao planejamento econômico, ora para conter as crises que permeavam o setor, ora para modernizar e tecnificar a atividade agroindustrial canavieira, ofertando subsídios, dentre outros estímulos ao processo de produção.

A análise focou a relação do Estado com a empresa canavieira no Brasil, em especial nas décadas finais do século $\mathrm{XIX}$ e ao longo do século $X X$, onde apareceram políticas públicas para o fortalecimento desse setor econômico. Por fim, foi traçada a trajetória de crescimento dos assalariados rurais no Brasil, ocorrido em virtude de alguns acontecimentos políticos gerados na segunda metade do século XIX. Também foram levantados os principais agentes e organizadores de classes, que reivindicam e atuam direta ou indiretamente pelos direitos dos assalariados rurais.

São agentes com interesse antagônicos e com parcelas de poder desproporcionais, que pendem para o lado da empresa canavieira. O Estado aparece como o campo estratégico de lutas políticas, nos termos de Poulantzas (1980). Sem pretender esgotar a complexidade da relação Estado-sociedade, entende-se que ele é poroso às demandas da sociedade, podendo, tanto ser o Estado-instrumento dos interesses das classes dominantes, quanto agente colaborador em processos de emancipação social, quando sob pressão, e por meio de movimentos de ocupação de espaços institucionais.

\section{POLÍTICAS ESTATAIS E A PRODUÇÃO CANAVIEIRA}

A expansão da Agroindústria Canavieira do Brasil que presenciamos atualmente é feita através do emprego, cada vez maior, de capital, e de alianças político-econômicas entre o Estado e o capitalista usineiro, os latifundiários, e dentre outros segmentos dominantes da nossa sociedade ligados ao setor agroindustrial brasileiro. 
A atividade canavieira no Brasil, desde a época em que o Brasil era colônia de Portugal, esteve fortemente ligada às relações político-econômicas e comerciais com a metrópole. A colônia seguia as ordens e atendia os interesses do país europeu. Como nos lembra Szmrecsányi (1979):

\begin{abstract}
A intervenção governamental na agroindústria canavieira tem uma longa história no Brasil, história essa que praticamente se confunde com a do próprio subsetor, o mais antigo e ainda um dos mais importantes ramos de atividades da economia nacional. Na verdade, o intervencionismo estatal na economia açucareira só não predominou durante o Império e nas primeiras décadas do regime republicano. Ele foi intenso durante todo o período colonial e voltou a acentuar-se depois da revolução de 1930, quando passou a assumir suas atuais características, entre as quais figuram com destaque o planejamento (SZMRECSÁNYI, 1979, p.161-162).
\end{abstract}

O século $X I X$, e as primeiras décadas do século $X X$ foram marcados pela expansão do liberalismo econômico europeu, onde o capital ditava as regras comerciais. O Brasil foi fortemente influenciado por essas relações capitalistas. No entanto, em meio às crises que abalavam a economia canavieira na segunda metade do século XIX, devido à concorrência com os demais países produtores como, por exemplo, Porto Rico e países filipinos, além das técnicas atrasadas de produção, os capitalistas usineiros recorriam ao Estado e ao planejamento estatal para livrarem de certas dificuldades.

Esses problemas que permeavam na economia canavieira levaram políticos e homens de negócios da época a se preocuparem com a modernização da lavoura e da industrialização açucareira, tanto que nas últimas décadas do século XIX, o Estado subsidiou e incentivou a construção de engenhos centrais, e em especial no centro-sul no país (TEIXEIRA, 1988).

O Parlamento brasileiro designou, em 1879, uma comissão Especial para proceder ao levantamento do estado da agricultura no país, especialmente o caso da cana-de-açúcar. A referida comissão elaborou, então, um parecer e projeto sobre a criação do banco de crédito territorial e fábricas centrais de açúcar, apresentado na sessão de 20 de julho daquele mesmo ano, na câmara dos deputados. A investigação parlamentar revelou seis problemas principais: 1) falta de treinamento profissional entre fazendeiros $e$ trabalhadores; 2) falta de transporte; 3) taxas altas; 4) carência de mão-deobra; 5) necessidade de divisão do trabalho e 6) falta de capital (SOUZA, 1978 apud TEIXEIRA, 1988, p.62). 
Dentre as principais carências apontadas, aparecem aquelas relacionadas às infra-estruturas e relações de trabalho, além dos custos de capital na produção. Os empresários capitalistas, quando se deparam a essas dificuldades, se refugiam ao Estado com o intuído de minimizar certas contradições no meio econômico. O Estado na sociedade capitalista tem o papel de subsidiar toda e infra-estrutura básica para o proveito das grandes empresas e dos capitalistas (MILIBAND, 1972), sejam em países desenvolvidos, ou subdesenvolvidos (SANTOS, 1970).

A Figura 1 apresenta os primeiros projetos de construção dos Engenhos Centrais, na segunda metade do século XIX. Na época, o Estado do Paraná recebeu recursos e construiu o seu Engenho Central na cidade de Morretes. Porém, essa atividade ficou bastante restrita à área serrana e não resultou em crescimento significativo do setor, ainda que até o presente existam naquela área pequenas unidades produtoras de aguardente (TEIXEIRA, 1988).

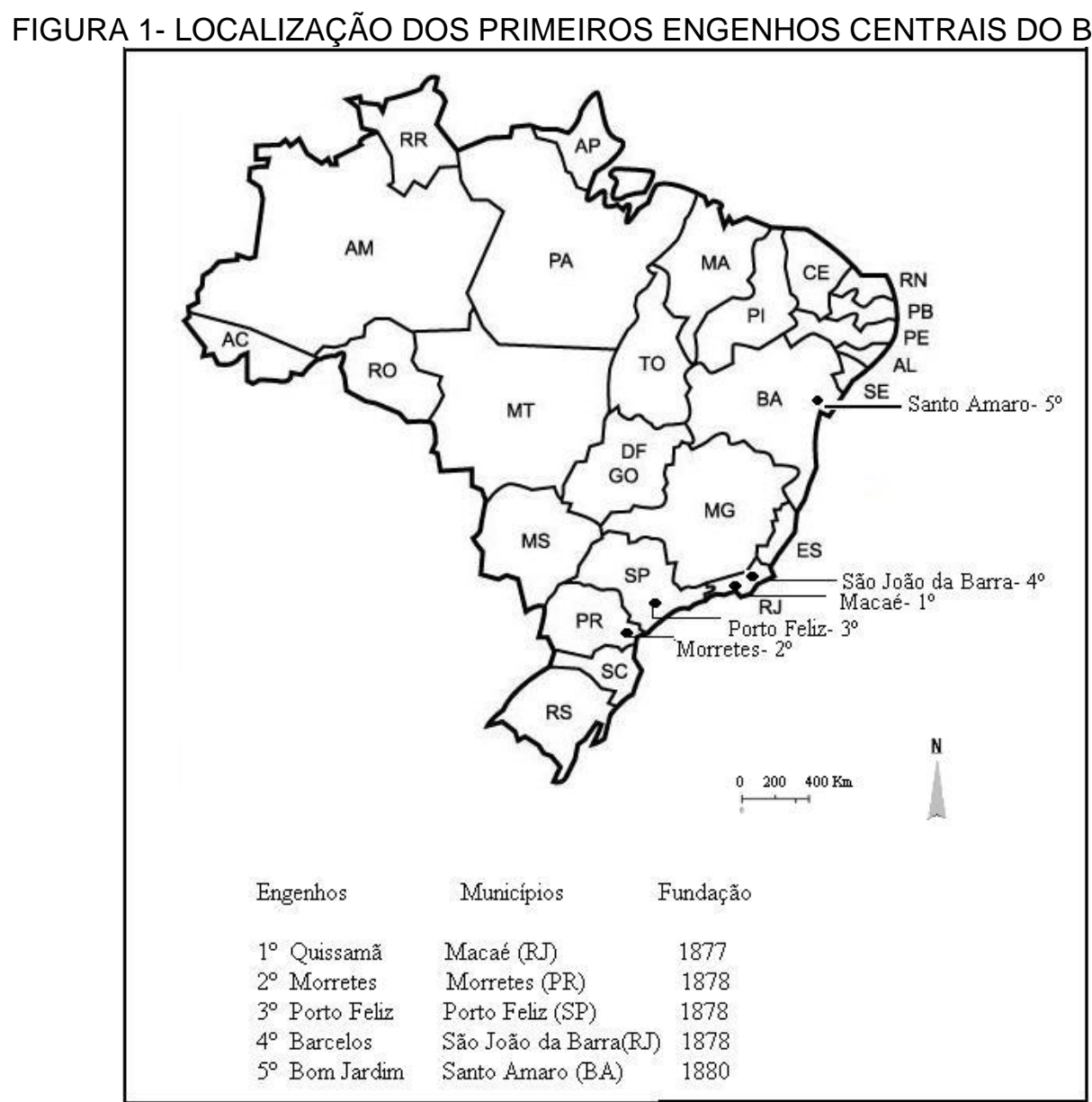

Fonte: TEIXEIRA, 1988.

Organização: RIBEIRO, V.H, 2009. 
Esse planejamento por parte do Estado para a melhoria da economia canavieira do Brasil através da construção dos Engenhos Centrais não surtiu o efeito esperado. Dentre os motivos que condicionaram a crise dos Engenhos Centrais, o país não conseguiu evitar a concorrência com os demais países produtores de açúcar, e com o açúcar de beterraba produzido pelos países europeus. Além do mais, ocorreram problemas internos como os citados por Souza (1978):

com o fornecimento da cana, a falta de braços, a má administração, a falta de planejamento nos transportes e no emprego de capitais e a inexperiência de muitos industriais. A estas somar-se-iam como causas imediatas: o desgaste das máquinas e as dificuldades na substituição de peças; mão-deobra especializada escassa e alguns técnicos charlatões atraídos pelo importante mercado de trabalho brasileiro; além de fato de que alguns dos intitulados Engenhos Centrais não passavam de simples engenhos que tinham melhorado os maquinários (SOUZA, 1978, XIII Apud TEIXEIRA, 1988, p.82).

Neste período, é válido ressaltar também, que a economia cafeeira acenava no mercado brasileiro como o principal produto econômico, destinado à exportação. Neste caso, as políticas de planejamento econômico-social por parte do Estado voltaram às principais regiões plantadoras de café. As demais atividades econômicas, como a cana-de-açúcar, entraram em crise. Surgiam outros ciclos econômicos, como o da Borracha na região Amazônia, e com isso houvera uma intensa mobilidade da força de trabalho para essas áreas de atração, e foram em especial migrantes nordestinos, oriundos da principal região brasileira da época produtora de açúcar. A atividade canavieira foi, então, necessitando cada vez mais de braços para a lavoura.

No entanto, é preciso considerar que o planejamento da construção dos Engenhos Centrais marca os antecedentes da relação do Estado e a economia canavieira no sentido de modernizar esta atividade no Brasil, antes da consolidação do Instituto do Açúcar e do Álcool, na década de 1930.

Em decorrência da crise de 1929, que abalou a economia mundial, e com o desenrolar da segunda guerra, a comercialização do açúcar brasileiro sentiu fortemente esse impacto no âmbito nacional e internacional, assim como outras atividades econômicas para a exportação da época. O comércio de açúcar da região nordestina para o centro-sul do país, que na época era feito pelo transporte marítimo 
no Oceano Atlântico, foi interrompido devido à guerra submarina. Neste caso, era necessário investir em outras localidades, sendo que o centro-sul do Brasil já mostrava indícios de industrialização. O Estado passa então a incentivar e a criar órgãos para a industrialização do açúcar e, também, políticas voltadas ao álcool combustível, pois assim o país dependeria menos da gasolina importada, cujo consumo interno não parava de crescer (SZMRECSÁNYI, 1979).

O álcool, que até a década de 1930 era considerado um subproduto da cana, destinando-se quase exclusivamente ao consumo doméstico e às incipientes indústrias químicas e farmacêuticas da época, depois da institucionalização do Instituto do Açúcar e do Álcool (IAA) ele passa a ser usado como carburante, e de subproduto ele se torna produto. Neste caso, o álcool deveria ser desidratado, se transformando em álcool anidro ou absoluto isento de água.

Para tais mudanças no setor canavieiro desta época era necessária a construção de grandes destilarias com aparelhamento moderno, além de enfrentar a concorrência da gasolina no mercado interno. Esses objetivos não poderiam ser alcançados sem a intervenção direta do Estado e,

\begin{abstract}
a primeira medida neste sentido foi o decreto $\mathrm{n}$. 19.717, de 20/02/1931. Estabelecia este decreto que a partir de 01/06/1931, o pagamento dos direitos de importação de gasolina somente poderia ser efetuado depois de feita a prova de haver o importador adquirido, para adicionar à mesma, álcool de procedência nacional, na proporção mínima de $5 \%$ sobre a quantidade de gasolina que pretendesse despachar, calculada em álcool a $100^{\circ}$. O mesmo decreto tornava obrigatório, para os automóveis de propriedade ou a serviço da União, dos Estados e dos Municípios, o consumo de carburante que contivesse, pelo menos, álcool na proporção de $10 \%$. Além disso, isentava de impostos e taxas a importação, até 31/03/1932, o material necessário à montagem de usinas para o fabrico e redistilação do álcool anidro e indispensável ao aperfeiçoamento e adaptação das destilarias existente no País (SZMRECSÁNYI, 1979, p.171).
\end{abstract}

O Estado veio, através desse decreto e de muitos outros, a interferir de forma direta na agroindústria canavieira, e em 1933, através do decreto n. 22.789 de 01/06/1933 o Governo Federal criava o Instituto do Açúcar e do Álcool (IAA).

O Instituto se encarregava então de dirigir, fomentar e controlar a produção de açúcar e de álcool em todo o país, passando a responder não apenas aos decretos e atribuições de órgãos que o procedera, mas também de outras atribuições que 
foram acrescidas com o passar dos anos (ANDRADE, 1950 abud SZMRECSÁNYI, 1979).

Szmrecsányi (1979, p. 180) apresenta as duas primeiras alíneas do artigo $4^{\circ}$ do Decreto n. 22. 789:

a) "Assegurar o equilíbrio interno entre as safras anuais de cana e o consumo de açúcar, mediante a aplicação obrigatória de uma quantidade de matéria prima, a determinar, ao fabrico do álcool";

b) "Fomentar a fabricação do álcool anidro, mediante a instalação de destilarias centrais nos pontos mais aconselháveis, ou auxiliando as cooperativas e sindicatos de usineiros que para tal fim se organizarem, ou os usineiros individualmente, a instalar destilarias ou melhorar suas instalações atuais".

Como se pode ver, os principais objetivos do Instituto era de promover o reerguimento da indústria açucareira, solucionando os impactos causados pela superprodução do produto devido à crise 1929, e incentivar a produção do álcool combustível através da construção de destilarias para essa finalidade. Em outras palavras, a participação do IAA foi mais expressiva em relação ao álcool do que no açúcar. Esta por sua vez teve os seus limites de produção, e quando a produção canavieira de um determinado Estado da federação excedia esses limites, os excedentes destinavam-se ao fabrico do álcool e seus derivados (SZMRECSÁNYI, 1979).

TABELA 1- PRIMEIROS LIMITES DE PRODUÇÃO DO AÇÚCAR DE USINA NO BRASIL

\begin{tabular}{|c|c|c|c|}
\hline \multirow[t]{2}{*}{ Estados Produtores } & \multicolumn{2}{|c|}{ Limites de Produção } & \multirow{2}{*}{$\begin{array}{c}\text { Data da resolução } \\
\text { do IAA }\end{array}$} \\
\hline & Sacos & $\%$ & \\
\hline \multicolumn{4}{|l|}{ Pará, Maranhão, Ceará e } \\
\hline Rio Grande do Norte & 54.443 & 0,4 & 24/9/1935 \\
\hline Paraíba & 225.912 & 1,9 & 24/9/1935 \\
\hline Pernambuco & 4.450 .193 & 37,6 & $11 / 3 / 1936$ \\
\hline Alagoas & 1.301 .928 & 11 & 23/12/1935 \\
\hline Sergipe & 721.519 & 6,1 & $1 / 10 / 1935$ \\
\hline Bahia & 685.101 & 5,8 & 16/9/1935 \\
\hline Minas Gerais & 339.599 & 2,9 & 9/7/1935 \\
\hline Rio de Janeiro & 2.000 .137 & 16,9 & $11 / 7 / 1935$ \\
\hline São Paulo & 2.067 .863 & 17,4 & $11 / 7 / 1935$ \\
\hline
\end{tabular}

Fonte: SZMRECSÁNYI, 1979. 
Esse limite na produção do açúcar por parte do governo federal na época, apontada pela Tabela 1, foi para conter a crise de 1929, quando muitos países deixaram de comprar o açúcar brasileiro. Esses limites tinham por objetivo conter a superprodução do açúcar no mercado interno, e, paralelamente a isso, o Brasil dava os primeiros passos na fabricação do álcool combustível tão importante para o processo de industrialização brasileiro. À época o país dependia da importação de outras fontes energéticas (TEIXEIRA, 2002).

As Tabelas 2 e 3 vêm apresentar a evolução da produção da cana-de-açúcar, e a produção açucareira no Brasil, respectivamente, no período em que o Instituto (IAA) interferiu nessa atividade econômica. Percebe-se que nos anos de 1930 houve um crescimento tímido da produção canavieira, dentre outros motivos, o Estado pusera um controle rígido na produção de açúcar pra conter as crises que permeavam a economia canavieira.

A produção canavieira vai aumentando consideravelmente nos anos finais da década de 1950 e nas décadas de 1960/70, pois, é o período de intensificação do parque industrial brasileiro, ocorrendo mudanças sócio, político e cultural no País, culminando com a urbanização brasileira em decorrência do êxodo rural-urbano, e, em virtude desses e dentre outros fatos, o Brasil precisava aumentar a produção canavieira pra disponibilizar matéria-prima necessária para suprir a demanda de açúcar e de álcool que o País necessitava.

Na primeira metade do século $\mathrm{XX}$, a principal localidade produtora de açúcar do País era a região Norte/Nordeste. Já na década de 1950 em diante, a região nordestina vai perdendo hegemonia, e o Centro/Sul do Brasil acenava como os principais produtores de açúcar do País (Tabela 3), principalmente com os investimentos e concessões de créditos por parte do Instituto do Açúcar e do Álcool (IAA) para a construção de usinas e destilarias nesta localidade (TEIXEIRA, 1988). 
TABELA 2- EVOLUÇÃO DA CULTURA CANAVIEIRA NO BRASIL.

\begin{tabular}{|c|c|c|c|}
\hline Anos & $\begin{array}{c}\text { Área } \\
\text { (1000 ha) } \\
\end{array}$ & $\begin{array}{l}\text { Produção } \\
\text { (1000 TM) } \\
\end{array}$ & $\begin{array}{c}\text { Rendimento } \\
\text { (TM/ha) } \\
\end{array}$ \\
\hline 1933 & 430 & 15.523 & 36 \\
\hline 1934 & 473 & 17.793 & 38 \\
\hline 1935 & 437 & 16.681 & 38 \\
\hline 1936 & 461 & 18.496 & 40 \\
\hline 1937 & 395 & 15.737 & 40 \\
\hline 1938 & 394 & 16.409 & 43 \\
\hline 1939 & 482 & 19.514 & 41 \\
\hline 1940 & 515 & 21.475 & 42 \\
\hline 1941 & 560 & 21.463 & 38 \\
\hline 1942 & 559 & 21.574 & 39 \\
\hline 1943 & 577 & 22.051 & 38 \\
\hline 1944 & 676 & 25.149 & 37 \\
\hline 1945 & 657 & 25.179 & 38 \\
\hline 1946 & 758 & 28.069 & 37 \\
\hline 1947 & 773 & 28.990 & 38 \\
\hline 1948 & 819 & 30.893 & 38 \\
\hline 1949 & 797 & 30.929 & 39 \\
\hline 1950 & 828 & 32.671 & 39 \\
\hline 1951 & 874 & 33.653 & 38 \\
\hline 1952 & 920 & 36.041 & 39 \\
\hline 1953 & 991 & 38.337 & 39 \\
\hline 1954 & 1.027 & 40.302 & 39 \\
\hline 1955 & 1.073 & 40.946 & 38 \\
\hline 1956 & 1.124 & 43.976 & 39 \\
\hline 1957 & 1.172 & 47.703 & 41 \\
\hline 1958 & 1.208 & 50.019 & 41 \\
\hline 1959 & 1.291 & 53.477 & 41 \\
\hline 1960 & 1.361 & 57.178 & 42 \\
\hline 1961 & 1.367 & 59.378 & 43 \\
\hline 1962 & 1.467 & 62.535 & 43 \\
\hline 1963 & 1.509 & 63.723 & 42 \\
\hline 1964 & 1.519 & 66.399 & 44 \\
\hline 1965 & 1.705 & 75.853 & 44 \\
\hline 1966 & 1.636 & 75.788 & 46 \\
\hline 1967 & 1.681 & 77.087 & 46 \\
\hline 1968 & 1.687 & 76.610 & 45 \\
\hline 1969 & 1.672 & 75.247 & 45 \\
\hline 1970 & 1.725 & 79.753 & 46 \\
\hline 1971 & 1.692 & 79.595 & 47 \\
\hline 1972 & 1.951 & 90.941 & 47 \\
\hline 1973 & 2.210 & 102.287 & 46 \\
\hline
\end{tabular}

Fonte: SZMRECSÁNYI, 1979.

Organização: RIBEIRO, V.H, 2010. 
TABELA 3- DISTRIBUIÇÃO ESPACIAL DA PRODUÇÃO AÇUCAREIRA DO BRASIL POR REGIÕES

\begin{tabular}{|c|c|c|c|c|c|}
\hline \multirow{2}{*}{ Safras } & \multirow{2}{*}{$\begin{array}{c}\text { Produção total } \\
1000 \text { sacos }\end{array}$} & \multicolumn{2}{|c|}{ Norte/Nordeste } & \multicolumn{2}{|c|}{ Centro/Sul } \\
\hline & & 1000 sacos & $\%$ & 1000 sacos & $\%$ \\
\hline $\begin{array}{l}1929 / 30 \\
1930 / 31 \\
1931 / 32 \\
1932 / 33\end{array}$ & $\begin{array}{c}10.804 \\
8.256 \\
9.157 \\
8.746\end{array}$ & $\begin{array}{l}7.431 \\
5.605 \\
5.650 \\
5.313\end{array}$ & $\begin{array}{l}69 \\
68 \\
62 \\
61\end{array}$ & $\begin{array}{l}3.373 \\
2.651 \\
3.507 \\
3.432\end{array}$ & $\begin{array}{l}31 \\
32 \\
38 \\
39\end{array}$ \\
\hline 1933/34 & 9.049 & 5.121 & 56,5 & 3.938 & 43,5 \\
\hline $1934 / 35$ & 11.136 & 7.155 & 64 & 3.981 & 36 \\
\hline $1935 / 36$ & 11.841 & 7.191 & 61 & 4.650 & 39 \\
\hline 1936/37 & 9.550 & 4.162 & 43,5 & 5.388 & 56,5 \\
\hline 1937/38 & 10.907 & 5.462 & 50,1 & 5.445 & 49,9 \\
\hline 1938/39 & 12.703 & 8.049 & 63,5 & 4.654 & 36,5 \\
\hline 1939/40 & 14.406 & 9.133 & 63,5 & 5.273 & 36,5 \\
\hline 1940/41 & 13.512 & 8.015 & 59,5 & 5.497 & 40,5 \\
\hline $1941 / 42$ & 13.839 & 7.743 & 56 & 6.096 & 44 \\
\hline $1942 / 43$ & 14.759 & 8.620 & 58,5 & 6.139 & 41,5 \\
\hline $1943 / 44$ & 15.314 & 9.525 & 62 & 5.789 & 38 \\
\hline $1944 / 45$ & 14.897 & 8.195 & 55 & 6.712 & 45 \\
\hline $1945 / 46$ & 15.418 & 8.256 & 53,5 & 7.162 & 46,5 \\
\hline $1946 / 47$ & 18.352 & 9.929 & 54 & 3.426 & 46 \\
\hline 1947/48 & 22.623 & 12.103 & 53,5 & 10.520 & 46,5 \\
\hline $1948 / 49$ & 23.579 & 12.740 & 54 & 10.839 & 46 \\
\hline 1949/50 & 21.140 & 10.083 & 48 & 11.057 & 52 \\
\hline $1950 / 51$ & 24.817 & 12.589 & 51 & 12.228 & 49 \\
\hline $1951 / 52$ & 26.596 & 11.841 & 44,5 & 14.754 & 55,5 \\
\hline 1952/53 & 30.802 & 14.792 & 48 & 16.010 & 52 \\
\hline $1953 / 54$ & 33.376 & 14.150 & 42 & 19.226 & 58 \\
\hline $1954 / 55$ & 35.568 & 15.193 & 43 & 20.375 & 57 \\
\hline $1955 / 56$ & 35.464 & 17.048 & 42 & 18.416 & 52 \\
\hline $1956 / 57$ & 37.580 & 17.396 & 46 & 20.187 & 54 \\
\hline $1957 / 58$ & 43.378 & 17.091 & 38,5 & 27.287 & 61,5 \\
\hline $1958 / 59$ & 53.859 & 17.805 & 33 & 36.054 & 67 \\
\hline $1959 / 60$ & 50.864 & 20.133 & 39,5 & 30.731 & 60,5 \\
\hline $1960 / 61$ & 54.350 & 19.967 & 37 & 34.383 & 63 \\
\hline $1961 / 62$ & 56.434 & 21.490 & 38 & 34.944 & 62 \\
\hline $1962 / 63$ & 51.079 & 16.773 & 33 & 34.306 & 67 \\
\hline $1963 / 64$ & 51.645 & 19.070 & 37 & 32.576 & 63 \\
\hline $1964 / 65$ & 59.422 & 21.042 & 35,5 & 38.380 & 64,5 \\
\hline $1965 / 66$ & 75.982 & 20.123 & 26,5 & 55.859 & 73,5 \\
\hline 1966/67 & 68.599 & 24.150 & 36 & 44.059 & 64 \\
\hline $1967 / 68$ & 70.261 & 24.666 & 35 & 45.595 & 65 \\
\hline $1968 / 69$ & 68.530 & 23.280 & 34 & 45.250 & 66 \\
\hline 1969/70 & 72.216 & 26.761 & 37 & 45.455 & 63 \\
\hline 1970/71 & 85.328 & 28.969 & 34 & 56.359 & 66 \\
\hline 1971/72 & 89.774 & 30.819 & 34,3 & 58.955 & 65,7 \\
\hline 1972/73 & 98.874 & 33.313 & 33,7 & 65.561 & 66,3 \\
\hline $1973 / 74$ & 111.382 & 32.926 & 29,6 & 78.456 & 70,4 \\
\hline $1974 / 75$ & 112.010 & 38.095 & 34 & 73.915 & 66 \\
\hline
\end{tabular}

Fonte: SZMRECSÁNYI, 1979.

Organização: RIBEIRO, V.H, 2010. 
Essa força do agronegócio canavieiro no Centro/Sul do Brasil não seria tão forte e significativo nos dias atuais se o Estado não interferisse diretamente na produção. O governo federal se fez presente nos momentos de crise do setor canavieiro: nas crises sofridas pela concorrência com outros países produtores de açúcar em meados do século XX; na modernização da atividade canavieira na década de 1930 com o IAA; na superprodução interna; no incentivo à produção do álcool combustível nas décadas de 1930 e posteriormente nos anos 1970/80; e atualmente com as políticas voltadas ao Etanol e aos biocombustíveis.

Além disso, Tomaz Júnior (2002) observa que a relação do Estado com a agroindústria canavieira

não restringe apenas às instâncias de planejamento e controle, bem como da fiscalização da produção, distribuição e comercialização dos produtos. Está presente também, assim como para as demais esferas da atividade econômica, na normatização e regramento jurídico-institucional das relações sociais de trabalho, com o atributo de realizar a mediação entre capital e trabalho. Nesse sentido, em consonância com as demandas e exigências do capital, o Estado delimita o raio de ação do trabalho, com base em pressupostos legais e institucionais, tentando, assim, condicionar o comportamento das entidades representativas dos trabalhadores em todas as suas instâncias da estrutura vertical oficial (sindicatos, federações e confederações) (THOMAZ JÚNIOR, 2002, p.56).

Percebe-se, então, que não é de hoje que o Estado interfere na economia canavieira do País. Sua intervenção é fruto de um longo processo histórico desencadeado no decorrer do século XX, que culminou com a acumulação de capital no ramo, e consolidou a moderna Agroindústria Sucroalcooleira atual.

Outro período que fomentou política por parte do governo federal para a agroindústria canavieira foi na crise energética dos anos 1970, quando os principais países árabes produtores de petróleo se organizaram (OPAEP) e aumentaram os preços do petróleo, sobrevalorizando seus produtos. Isso desencadeou diversas crises na economia mundial, e em especial na economia brasileira, o país dependia quase inteiramente do transporte rodoviário e produzia pouco petróleo, ficando numa situação crítica e levando o governo federal a um programa de planejamento que "o liberasse em parte da importação do petróleo, e que também dinamizasse a 
indústria canavieira (...) com a concessão de empréstimos aos industriais que dispusessem a montar destilarias” (QUEIROZ, 2007, p.22)

O governo federal, com o objetivo de minimizar as importações de petróleo, criou o Programa Nacional do Álcool em 1975.

O PROÁLCOOL foi instituído através do Decreto 76.593 de 14/11/1975. É um programa federal, administrativo pelo Ministério da Indústria e Comércio através da CENAL- Comissão Executiva Nacional do Álcool, cujo objetivo foi o de expandir a produção de álcool, e a capacidade industrial de transformação, visando à obtenção de álcool para a substituição da gasolina, assim como incrementar o uso no setor químico, cujo intuito foi o de minimizar o desequilíbrio da balança de pagamento (TEIXEIRA, 1988, p.218).

O Programa Nacional do Álcool teve duas fases importantes que resultou num aumento da produção canavieira em áreas tradicionais de açúcar: A primeira em 1975/ 79, quando ocorreu o financiamento para a montagem e ampliação das destilarias anexas às usinas, e a fabricação de álcool anidro para ser misturado à gasolina. A segunda foi a expansão acelerada (1980-1986), onde aumenta significativamente produção de álcool hidratado para o uso de motores exclusivos a álcool, e as plantações de cana-de-açúcar se expandem para áreas até então ocupadas por outras culturas. Também nessa fase acelerada houve a montagem de novas destilarias (RIBEIRO, 2008).

O Programa Nacional do Álcool, mesmo passando por diversas crises ao longo da década de 1980, deu forma à moderna agroindústria sucroalcooleira do País atualmente. Muitas usinas e destilarias anexas às mesmas em atividades nos dias de hoje são resultados desse processo. Além disso, a fabricação de carros destinados a mover a álcool também fez parte do processo. No presente, devido às complicações sócio-ambientais acerca do petróleo e as especulações políticas e econômicas entorno do mesmo, o álcool e a produção de carros flex-fuel, que podem ser rodados com álcool, gasolina, ou na mistura dos dois combustíveis, vem impulsionando o crescimento do setor alcooleiro do Brasil (TOMAZ JÚNIOR, 2007).

Esse crescimento do setor ocorreu graças às políticas incrementadas por parte do Estado, no sentido de fomentar e incentivar as montadoras de veículos a produzirem carros flex-fuel, além das políticas de exportação do Etanol brasileiro. 
Esse incentivo do Estado às agroindústrias sucroalcooleiras gerou mobilidade da força do trabalho no território brasileiro, na medida em que esse setor se concentrou no centro-sul do País. São trabalhadores de várias regiões do Brasil que se deslocam para os canaviais do centro-sul, na esperança de melhores condições de vida. No entanto, o que se presencia são trabalhos altamente exaustivos e, muitas vezes, análogos à escravidão conforme denúncias por parte do ministério do trabalho, principalmente nos Estados de São Paulo, e no norte-nordeste do Brasil (ZAFALON, 2007).

\section{O ESTADO E OS TRABALHADORES RURAIS}

A história do relacionamento entre o Estado e os trabalhadores rurais no Brasil, principalmente no decorrer dos séculos XIX e XX, é a história da proletarização da mão-de-obra rural. É a história do progressivo, mas ao mesmo tempo contraditório processo de separação entre a propriedade dos meios de produção e a propriedade da força de trabalho. É a história entre as relações do trabalhador e o empresário, ou, em outras palavras, do colono, do morador, do agregado, empregado, camarada, volante, bóia-fria, peão, assalariado permanente e temporário, de um lado, e, por outro, do fazendeiro, usineiro, criador, empreiteiro de mão-de-obra ou gato (IANNI, 1977).

No decorrer da separação da propriedade de produção e da força de trabalho, - Estado esteve presente no processo na medida em que condicionou alguns acontecimentos político-econômicos importantes, como observa lanni (1977, p.1):

Primeiro, a extinção do tráfico de escravos, a imigração de braços para a lavoura, a lei do Ventre Livre e a lei dos Sexagenários, entre 1850 e 1885. Segundo, a abolição do regime de trabalho escravo, em 1888, e a grande naturalização dos imigrantes, estabelecida pela constituição de 1891. A abolição e a naturalização geral dos imigrantes que nada declarassem em contrário ao estipulado na constituição, foram atos políticos que instituíram o trabalho livre, o trabalhador como cidadão. Terceiro, o regime de trabalho livre vigente na fazenda de café, desde a segunda metade do século XIX até 1930 , foi o regime de colonato, que se estruturou em forma jurídico-política, segundo leis especiais. Quarto, no ciclo amazônico da borracha, que teve o seu apogeu nos anos 1890-1912, não houve 
qualquer tentativa do poder público no sentido de garantir alguma reivindicação ou algum direito ao seringueiro. O sistema de aviamento, que era baseado numa cadeia de endividamentos, subjugava o seringueiro ao seringalista, este ao aviador e o aviador ao exportador de borracha. Quinto, a consolidação das Leis do Trabalho (CLT), promulgada pela ditadura do Estado Novo, em 1943, não contemplava, se não um plano muito secundário, algumas reivindicações do proletariado rural. Aliás, o Estatuto da Lavoura Canavieira, de 1941, em seus artigos 19 a 26, procurava garantir a condição de morador para o trabalhador do canavial. Esse estatuto reeditava alguns dos dispositivos que haviam sido estabelecidos no começo do século para o colonato da fazenda de café. Sexto, em 1963 promulgou-se o Estatuto do Trabalhador Rural, no qual, pela primeira vez na história social do trabalho agrícola, definem-se em forma relativamente sistemática as condições político-econômicas do contrato de trabalho na agricultura brasileira; e não apenas na cafeicultura ou na agroindústria canavieira.

O Estado se fez assim presente ao longo da história dos trabalhadores rurais livres no Brasil, preparando, então, o terreno para a agricultura capitalista no País. A história dos trabalhadores da cana-de-açúcar no território brasileiro está ligada a esse processo de proletarização dos trabalhadores rurais. Como vimos no item anterior, as políticas e planejamento econômico por parte do Estado no setor agroindustrial canavieiro tão pouco, ou quase nada, dava atenção aos trabalhadores rurais, em especial aos bóias-frias.

As políticas e planejamento por parte do IAA e do PROÁLCOOL voltaram-se, exclusivamente, ao planejamento econômico do setor. As lutas e reivindicações dos trabalhadores bóias-frias aconteceram com o tempo, na organização e mobilização dos mesmos, no território nacional. Corroborou com isso, a questão da reforma agrária e as revoltas como em Porecatu e no sudoeste do Paraná, Trombas e Formoso no Estado de Goiás, e dentre outras, ou devido à formação de diversas organizações, como as Ligas e sindicatos, nos anos 50 e 60, que houve a preocupação de formular uma legislação que atendessem suas necessidades (PRIORI, 1996, p.7).

A segunda metade do século $X X$ foi marcada pelas revoltas e contradições no meio rural brasileiro, pois até então, as legislações trabalhistas voltavam-se apenas aos trabalhadores urbanos, devido ao contexto histórico dessa classe de trabalhadores no processo de industrialização brasileiro (PRIORI, 1996). A exemplo do que vinha de fora, dos trabalhadores se organizando dentro de partidos de 
esquerda, a burguesia industrial brasileira passa então a ceder algumas reivindicações para os trabalhadores urbanos, a fim de controlar-los, e camuflar as contradições entre patrão e empregados, que poderiam gerar lutas de classes e ameaçar o domínio da burguesia industrial sobre o operariado urbano.

Neste caso, as Leis Trabalhistas no meio rural brasileiro só foram criadas e consolidadas, principalmente depois dos anos 1950 quando intensifica a concentração de terras no País, com o advento da modernização da atividade agrícola que promoveu o êxodo rural-urbano, e gerou diversas revoltas no território brasileiro. Neste momento, as principais políticas por parte do Estado para com os trabalhadores rurais surgiram do Serviço Social Rural (SSR), do então presidente da época, Getúlio Vargas, que sinalizava algumas medidas que proporcionavam um padrão de vida melhor para o homem do campo, já que a população urbana constituía de uma camada social mais alfabetizada e educada, além de dispor de uma renda média elevada em relação à população rural (PRIORI, 1996). Vargas (1969) ressalta que a população rural era

\begin{abstract}
desprovida de amplas possibilidades de ensino e de serviços sociais de modo geral, subalimentada, exposta a graves endemias, com renda baixa e freqüentemente instável, vegeta num nível mínimo de existência quase inteiramente à margem de quaisquer providências da política social que, em tão ampla escala, beneficia a população urbana. Pode-se asseverar que o habitante do campo vive, até certo ponto, num quadro cultural de séculos passados, acusando pouca influência do progresso técnico, social, educacional dos tempos modernos (VARGAS, 1969, p.11-12).
\end{abstract}

A política de Serviço Social Rural de Vargas antecede o Estatuto do Trabalhador Rural (ETR) dos anos de 1960. Nesta época, intensifica o processo de modernização das técnicas de produção no campo, e, na medida em que se diversifica a empresa agrícola, a pecuária, a agroindústria etc, desenvolve-se a legislação de trabalho no campo e o Estado passa a estabelecer diretrizes jurídicas, ou melhor, condições político-econômicas, destinadas a organizar ou reorganizar as relações de produção (IANNI, 1977, p.14).

Em se tratando dos trabalhadores da agroindústria canavieira, a Lei ㄲo 4.870 de 1 de Dezembro de 1965 conferia ao dono do canavial o total monopólio de assistência social: 
Seja residente ou não, o assalariado permanente da fazenda de cana ou usina é levado a receber a assistência como um favor do empresário, antes do que uma parte do direito seu. A forma pela qual pode ser aplicada a legislação relativa à assistência social aos trabalhadores das usinas, destilarias e canaviais permite que 0 usineiro e 0 fazendeiro aumentem 0 seu controle político sobre os operários rurais e industriais (IANNI, 1977, p.10).

Esse controle político por parte dos usineiros corroborava com o tipo de trabalho ofertado pelo setor sucroalcooleiro, e em especial se tratando do corte da cana-de-açúcar. Como sabemos hoje, devido às várias denúncias por parte do Ministério do Trabalho, além de estudos já realizados acerca desta problemática, os trabalhadores rurais bóias-frias realizam os trabalhos mais exaustivos e degradantes no meio rural, onde, em muitos casos, podem vir a óbitos por exaustão, fruto de paradas cardiovasculares etc.

Alguns autores vieram ao longo da segunda metade do século $X X$ relatar as condições precárias desse serviço ofertado pela agroindústria canavieira no Brasil, dentre eles, Maria Conceição D’ Incão e Mello em O Bóia fria acumulação e miséria, ressalta que, além da concentração da propriedade fundiária nas mãos dos poucos fazendeiros, faz um paralelo com o êxodo rural-urbano e a exploração da força de trabalho no meio rural. O pequeno agricultor que, depois de se separado da sua propriedade dos meios de produção e da força de trabalho, migrando para o meio urbano, tiveram que se proletarizar no corte de cana, serviço de baixa remuneração, além de ouvir relatos de mortes de trabalhadores no eito de trabalho (D'INCÃO, 1975).

Relatos como esses também encontramos em Silva (1999) onde ressalta quais são os agentes do processo de exploração-dominação no eito da cana, ou em outras atividades agrícolas que necessitem de trabalhadores temporários, como na citricultura, entre outras.

Esse processo de exploração e dominação dos capitalistas foi observado por Thomaz Júnior (2002), que apontou como principal legitimador nesse processo o Estado, que lançava mão de leis frágeis para controlar essa exploração. É a relação dos "sujeitos sociais" (capitalistas, trabalhadores e Estado) no processo de reprodução do sistema capitalista, contraditório, sendo que o Estado aparece a 
serviço dos capitalistas, na medida em que vem enfraquecendo e fragmentando os sindicatos dos trabalhadores rurais, e dificultando, então, a atuação dos mesmos na luta pelas reivindicações e direitos por parte dos trabalhadores.

Em pleno século $X X I$, com toda a modernização que vem passando a agroindústria canavieira no Brasil, trazendo divisas para o País devido à exportação do Etanol, ainda existem resquícios de trabalhos arcaicos análogos à escravidão que perpetuou mais de três séculos no território brasileiro. São trabalhadores de outras regiões brasileiras que migraram para cidades do centro-sul do país para trabalharem no corte da cana, que vieram a falecer em cidades onde praticam essa atividade.

As informações a seguir nos apresentam o histórico dos cortadores de cana mortos no setor canavieiro paulista, retirados do banco de dados da PASTORAL DO MIGRANTE, (2009):

\section{- CASOS DE 2004}

1. José Everaldo Galvão, 38 anos, natural de Araçuaí-MG, falecido em abril de 2004, no hospital de Macatuba-SP. Causa da morte: parada cardiorrespiratória. Sepultado em Araçuaí - MG.

2. Moises Alves dos Santos, 33 anos, natural de Araçuaí-MG, falecido em abril de 2004, no hospital de Valparaiso-SP. Causa da morte: parada cardiorrespiratória. Sepultado em Araçuaí - MG.

3. Manoel Neto Pina, 34 anos, natural de Caturama - BA, falecido em maio de 2004 no hospital de Catanduva-SP. Causa da morte: parada cardiorrespiratória. Sepultado em Palmares Paulista-SP.

\section{- CASOS DE 2005}

4. Lindomar Rodrigues Pinto, 27 anos, natural de Mutans - BA, falecido em março de 2005, em Terra Roxa_SP. Causa da morte: parada respiratória. Sepultado em Mutans-BA.

5. Ivanilde Veríssimo dos Santos, 33 anos, natural de Timbiras-MA. Causa da morte: pancreatite aguda. Sepultada em julho de 2005 em Pradópolis-SP. 
6. Valdecy de Paiva Lima, 38 anos, natural de Codó-MA. Faleceu em julho de 2005 no Hospital São Francisco de Ribeirão. Causa da morte: acidente cerebral hemorrágico. Sepultado em Codó-MA.

7. José Natalino Gomes Sales, 50 anos, natural de Berilo - MG. Falecido em agosto de 2005, no hospital de Batatais-SP. Causa da morte: parada cardiorrespiratória. Sepultado em Francisco Badaró - MG.

8. Domício Diniz, 55 anos, natural de Santana dos Garrotes - PB. Falecido em setembro de 2005, em trânsito para o hospital em Borborema, SP. Causa da morte: desconhecida.

Sepultado em Borborema-SP.

9. Valdir Alves de Souza, 43 anos. Falecido em 04 de outubro de 2005 em Valparaíso-SP. Não temos outras informações.

10. José Mario Alves Gomes, 45 anos, natural de Araçuaí-MG. Faleceu em Rio das Pedras, em 21 de outubro de 2005. Causa da morte: ignorada. Foi sepultado em Araçuaí-MG.

11. Antonio Ribeiro Lopes, 55 anos, natural de Berilo-MG. Faleceu em 23 de novembro de 2005 em Guariba - SP. Causa da morte: edema hemorrágico pulmonar e cardiopatia dilatada descompensada. Foi sepultado em GuaribaSP.

\section{- CASOS DE 2006}

12. Juraci Santana, 37 anos, natural de Elesbão Veloso - PI. Faleceu no dia 29 de junho de 2006, no município de Jaborandi - SP. Causa da morte: desconhecida. Foi sepultado em Elesbão Veloso - PI.

13. Maria Neusa Borges, 54 anos, residente em Monte Alto. Faleceu no dia 24 de julho. Causa da morte: desconhecida. Foi sepultada em Monte Alto-SP.

14. Celso Gonçalves, 41 anos. Faleceu no dia 26 de julho de 2006 em TaiaçúSP. Causa da morte: desconhecida. Foi sepultado em Monte Alto, SP.

15. Oscar Almeida, 48 anos. Faleceu em Itapira dia 15 de setembro de 2006. Causa da morte: desconhecida. Foi sepultado em Conchal, SP. 


\section{- CASOS 2007}

16. José Pereira Martins, 51 anos, natural de Araçuaí-MG, residente em Guariba SP. Faleceu no dia 28 de março de 2007. Causa da morte: enfarto do miocárdio. Foi sepultado em Guariba-SP.

17. Lourenço Paulino de Souza, 20 anos, natural de Axixá do Tocantins - TO e morava em Colina - SP. Faleceu no dia 24 de abril de 2007. Causa da morte: desconhecida. Foi sepultado em Vila Tocantins - TO.

18. Adailton Jesus dos Santos, 34 , natural de São Raimundo Nonato - PI, faleceu no dia 19 de maio de 2007, no Hospital das Clínicas de Ribeirão Preto. Residia em Cravinhos. Causa da morte: choque anafilático causado por infecção. Foi sepultado em São Raimundo Nonato - PI.

19. José Dionísio de Souza, 33 anos, natural de Salinas - MG e morava na cidade de Ipaussu, no interior paulista. Faleceu no dia 20 de junho de 2007. Causa da morte: desconhecida. Seu corpo foi levado para o povoado de Fruta de Leite - MG.

20. Edilson Jesus de Andrade, 28 anos, natural de Tapiramutá-BA, faleceu no dia 11 de setembro de 2007. Residia em Guariba. O atestado de óbito do hospital aponta como causa da morte uma doença auto-imune, chamada púrpura trombocitopênica idiopática. Seu corpo foi sepultado em Guariba.

\section{- CASOS 2008}

21. Mariano Baader, de 53 anos, faleceu no dia 19 de maio de 2008. Residia em Presidente Prudente [SP]. O atestado de óbito do hospital aponta como causa da morte se deu em decorrência de parada cardiorrespiratória por causa indeterminada.

22. José Ilton Farias Guimarães, 32 anos, natural de Bom Conselho -PE. Faleceu em maio de 2008 em Ibaté - SP. No atestado de óbito a causa está como enfarto súbito.

\section{- CASOS 2009}

21. Adeilton dos Santos da Silva, 33 anos, solteiro, natural d Maceió AL. Trabalhava na Usina Campestre, faleceu no dia 12de agosto de 2009 na 
cidade de Avanhandava - SP. Causa da morte: Hemorragia digestiva. Foi sepultado em Messias - AL.

Nota-se que a maioria dos trabalhadores veio do Norte e Nordeste do Brasil, e alguns de Minas Gerais. Essa mobilidade da força de trabalho no setor canavieiro paulista se dá em virtude dos investimentos e incentivos ao setor, fruto das políticas e empreendimentos do IAA e do PROÁLCOOL. O Nordeste, que até os anos de 1950 era o principal produtor de cana-de-açúcar do Brasil, posterior a essa data, e principalmente com a modernização das técnicas de produção no meio rural nas décadas de 1970/80, a região nordestina vem sendo ultrapassada pela atividade sucroalcooleira do centro-sul do país. Isso fez surgir mobilidade da força de trabalho no setor, pois a lavoura canavieira é uma das atividades agrícolas que mais emprega mão-de-obra no meio rural. E foram em especial migrantes nordestinos para o "mar de cana" do Estado paulista.

As principais doenças que levaram a óbitos os trabalhadores apontados anteriormente estão relacionadas às doenças cardiorrespiratórias, dentre os principais motivos, devido à exaustão no eito de corte. E nota-se que a idade dos mesmos varia, dos 20 aos 50 anos. Jovens, e adultos, e em alguns casos idosos são vítimas do trabalho exaustivo da cana, e os meios de comunicação pouco divulgam esses casos, camuflando muitas vezes os motivos que lavaram a morte.

Essa superexploração fez com que os trabalhadores se organizassem em entidades estatais ou de classes como, por exemplo, em sindicatos dos trabalhadores rurais, ou no próprio movimento dos trabalhadores, com objetivos pautados nas melhorias salariais, além de reivindicações contra essa exploração no canavial. Organização e mobilização clássica acerca desta problemática foi o protesto social em Guariba, em maio de 1984, desencadeado em virtude do aumento do trabalho no corte de cana, e a manutenção do salário até então, que mal dava para pagar suas necessidades básicas (PENTEADO, 2000).

Essa época, na década de 1970/80, foi um período de grandes agitações sociais no Brasil, tanto no meio rural quanto no meio urbano. Foi o momento em que surgiram muitas organizações de classes dentro do sindicalismo brasileiro, como a Central Única dos Trabalhadores (CUT), ou movimentos populares dentro da igreja católica como a Pastoral da Terra (CPT), e dentre outros. Esses movimentos 
revelavam, aos poucos, o movimento contraditório da sociedade brasileira, fruto da relação e exploração do capital sobre o trabalho (THOMAZ JÚNIOR, 2002).

Se por um lado o Estado e o poder estatal promovem a acumulação de capital por parte dos agroindustriais, por outro é através dele que os trabalhadores se organizam e reivindicam direitos já conquistados através do Estatuto do Trabalhador rural. Além do Estado, também existem grupos de pressão que atuam entre a sociedade e o Estado, exercendo influências dentro das organizações partidárias atuantes em momentos de eleição, trazendo consigo a problemática da realidade brasileira, seja no meio urbano, seja no meio rural.

Sobre os grupos de pressão, Bonavides (1978, p.535-536) assinala que

\begin{abstract}
São organizações da esfera intermediária entre o indivíduo e o Estado, nas quais um interesse se incorporou e se tornou politicamente relevante. Ou são grupos que procuram fazer com que as decisões dos poderes públicos sejam conformes com os interesses e as idéias de uma determinada categoria social. (...) Os grupos de pressão não são outra coisa se não as forças sociais, profissionais, econômicas e espirituais de uma nação, enquanto aparecem organizadas e ativas.
\end{abstract}

Contudo, isso depende também da filosofia do partido político que está no poder, se for de esquerda ou direita, se está mais ao lado dos capitalistas e da economia moderna ou dos trabalhadores, influência nas decisões e nas conquistas dos grupos de pressão. Vale lembra que estes, além de estarem presentes nos grupos sociais, estão também nos grupos econômicos dominantes da sociedade. São pessoas que influenciam fortemente o andar do governo no decorrer do seu mandato.

Em prol das reivindicações dos trabalhadores da cana estão alguns grupos que atuam nos meios de comunicações, denunciando o sistema precário de serviço ofertado por algumas usinas brasileiras. A Pastoral do Migrante ressalta o cotidiano dos trabalhadores, suas origens e destinos, além da exploração do trabalhador rural das usinas. A Pastoral da Terra desde a segunda metade do século $X X$ vem atuando no meio rural, organizando os trabalhadores através de fóruns e entidades como o Grupo de Articulação dos Assalariados Rurais Temporários (GAART) formado por lideranças surgidas entre os bóias-frias, e se constituiu e ganhou forças 
na segunda metade de década de 1990 (BROIETTI, 2003), e o Fórum de Entidades que atuam junto ao Assalariado Rural Temporário (FEAJART).

Além desses e dentre outros fóruns, a CPT organiza também a Romaria da Terra que tem por objetivo a reflexão, a politização, a esperança e luta pela libertação dos assalariados rurais na busca pela conquista da cidadania, dos direitos sociais, além de melhores condições de vida (BROIETTI, 2003).

Em virtude da ausência do Estado na área social, ou pelo seu enfraquecimento em decorrência dos estímulos às organizações capitalistas internacionais e nacionais, esses grupos vêm a atuar e fazer o papel que o Estado deveria fazer: de se responsabilizar da sociedade como um todo. Em muitos casos, as leis e as organizações trabalhistas são pautadas para o fim de legitimar a geração de maisvalia por parte dos capitalistas e, conseqüentemente, aumentar os lucros deste segmento, enquanto que os trabalhadores são cada vez mais explorados e dominados por esse modo de produção.

\section{CONSIDERAÇÕES FINAIS}

É possível observar, a partir das reflexões contidas neste texto, a força do agronegócio canavieiro no país, que condicionou, em períodos históricos distintos, políticas públicas por parte do governo federal a seu favor. Neste caso, percebe-se a relação intrínseca entre o Estado e os capitalistas canavieiros, no processo de modernização do setor no país. Isso exige nossa atenção, pois é preciso acompanhar esse processo e avaliar as implicações que tem trazido de modo geral para a sociedade brasileira, e em especial para os trabalhadores que participam, de maneira desigual, no processo de produção do setor.

Há que se observar, entretanto, que a última década foi marcada por políticas sociais capazes da reversão dos piores indicadores de miséria do Brasil.

Políticas públicas vigorosas e corajosas voltadas aos trabalhadores da canade-açúcar somadas às mobilizações sindicais e das demais organizações de classes, podem reverter o quando da extrema exploração destacado neste texto. Políticas públicas são eficazes e emancipatórias no momento em que são 
elaboradas pela população-alvo e/ou seus representantes e têm potencial para reverter o quadro de precarização do trabalho na cana-de-açúcar.

\section{REFERÊNCIAS}

BONAVIDES, Paulo. Ciência Política. 4ำ edição. Rio de Janeiro. Forense. 1978. $627 p$.

BROIETTI, Marcos Henrique. Os assalariados Rurais temporários da cana. $1^{\underline{a}}$ edição, UFSC, 2003, 114p.

D’ INCÃO. Maria Conceição. O bóia fria. Acumulação e miséria. Petrópolis. Vozes. 1975. 154p.

IANNI, Octávio. O Estado e o trabalhador rural. Contexto. São Paulo, nํ4, p.1-15, Nov. 1977.

MILIBAND, Ralph. O Estado na sociedade capitalista. Rio de Janeiro. Zahar. 1972. 334p.

PASTORAL DO MIGRANTE. Disponível em: http://www.pastoraldomigrante.com.br/index.php?option=com_content\&view=article\& id=102:historico-dos-cortadores-de-cana-mortos-no-setor-canavieiro-

\&catid=25:dados. Acesso em: 27/11/2009.

PENTEADO, Maria Antonieta G. Trabalhadores da cana. Protesto social em Guariba-maio de 1984. Maringá. EDUEM. 2000. 236p.

POULANTZAS, N. O Estado, o poder, o socialismo. Rio de Janeiro: Edições Graal, 1980.

PRIORI, Ângelo. O protesto do trabalho. Maringá. EDUEM. 1996. 99p.

QUEIROZ, S.S. Uma aplicação do EVA (Economic Value added) para a Agroindústria Canavieira do Paraná. Mestrado, Universidade Estadual do Oeste do Paraná, Toledo, 2007, 103 p.

RIBEIRO, Vitor Hugo. O avanço do setor sucroalcooleiro do Paraná: dos engenhos às usinas. 2008. 60 f. Trabalho de conclusão de curso (Graduação em Geografia). Universidade Estadual de Maringá, Maringá, 2008.

SANTOS, Milton. O espaço dividido: os dois circuitos da economia urbana dos países subdesenvolvidos. Rio de Janeiro. Francisco Alves. 1979. 345p.

SILVA, Maria Aparecida de Moraes. Errantes do fim do século. São Paulo. Fundação UNESP, 1999, 370p.

SZMRECSÀNYI, Tamás. O Planejamento da agroindústria canavieira do Brasil (1930-1975). São Paulo. HUCITEC. 1979. 540p. 
TEIXEIRA, Wilson Antonio. As Transformações no Espaço Agrário do Paraná, com a introdução da Agricultura Energética Canavieira. Mestrado, UNESP, Rio Claro, 1988, 281p.

0 processo de desenvolvimento geoeconômico do complexo agroindustrial cooperativista na mesorregião Norte Central paranaense. 2002, 343f. Tese (Doutorado em Geografia) - Faculdade de Ciências e Tecnologia, Universidade Estadual Paulista, Presidente Prudente.

THOMAZ JÚNIOR, Antonio. Por trás dos canaviais, os "nós" da cana: a relação capital $x$ trabalho e o movimento sindical dos trabalhadores na agroindústria canavieira paulista. São Paulo. Annablume. 2002. 388p.

. Não há nada de Novo sob o Sol num Mundo de Heróis!

(A Civilização da Barbárie na Agroindústria Canavieira). Pegada Eletrônica, vol. 8, no 2, Dez. 2007. Disponível em: < http://www4.fct.unesp.br/ceget/ > acesso em: 13 de set. 2008.

VARGAS, Getúlio. O Governo trabalhista do Brasil. Rio de Janeiro. José Olympio. V. III. 1969. 500p.

ZAFALON, Mauro. Cortadores de cana têm vida útil de escravo em SP. Folha de São Paulo. São Paulo, 29 de abr. 2007, Dinheiro.

(Recebido em maio/2010. Aceito em dezembro/2010) 